\title{
Campaña y Velázquez: paralelos artísticos
}





\title{
Campaña y Velázquez: paralelos artísticos
}

\section{Campaña and Velázquez: artistic parallels}

\author{
Álvaro Cabezas García \\ Universidad de Sevilla (España) \\ alvarocabezasgarcia@gmail.com
}

Fecha de recepción: 28 de diciembre de 2019

Fecha de aceptación: 22 de enero de 2021

\section{Resumen}

Contribuir a la comprensión de la pintura de Diego Velázquez es el objetivo principal de este estudio, que pretende señalar alguna de las latentes raíces hispalenses que el genial artista llevó consigo y desarrolló con posterioridad en su dilatada etapa madrileña. Un mero apunte para alcanzar ese propósito podría establecerse poniendo en relación la tabla que representa a San Pablo Ermitaño y San Antonio, pintada por Pedro de Campaña, y el lienzo que, con un tema similar, ejecutó Velázquez: Encuentro de San Antonio Abad con San Pablo, primer ermitaño.

Palabras clave: Velázquez, Diego (1599-1660); Campaña, Pedro de (15031587); Pintura; Manierismo; Barroco.

\begin{abstract}
To contribute to the comprehension of the painting of Diego Velázquez is the main objective of this study, is to point out some of the latent sevillian roots that the artist kept in his extensive Madrid's stage. In this logic, I would like to analyze the relationships arising from the comparison of the table that represents to San Pablo Ermitaño y San Antonio by Pedro de Campaña, and the painting of Velázquez with a similar theme: Encuentro de San Antonio Abad con San Pablo, primer ermitaño.
\end{abstract}

Keywords: Velázquez, Diego (1599-1660); Campaña, Pedro de (15031587); Painting; Mannerism; Baroque. 


\section{INTRODUGGIÓN}

La cultura visual es una de las cuestiones fundamentales que cimentan tanto la formación como el desarrollo del proceso creativo de un artista. Detectar, analizar y poner en relación alguno de estos elementos -que conforman, al fin y al cabo, la base del genio, el talento y la inspiración-, permite aumentar el conocimiento sobre un determinado maestro. Contribuir a la comprensión de la pintura de Diego Rodríguez de Silva y Velázquez (Sevilla, junio de 1599 - Madrid, 6 de agosto de 1660), es el objetivo principal del presente estudio. Para ello, me gustaría señalar alguna de las latentes raíces hispalenses que el genial artista llevó consigo y desarrolló con posterioridad en su dilatada etapa madrileña (desde 1622-1623 hasta el momento de su muerte), ya que en demasiadas ocasiones se ha establecido una limpia cesura entre su primera etapa formativa en Sevilla y la posterior del reconocimiento regio en la corte (Angulo, 1947-1999; Maravall, 1960-1999; Brown, 1986 y Harris, 2006). Un mero apunte para alcanzar ese propósito podría establecerse poniendo en relación la tabla de San Pablo Ermitaño y San Antonio (Sevilla, parroquia de San Isidoro, c.1545, 221 x $231 \mathrm{~cm}$ ), pintada por Pedro de Campaña (Bruselas, c.1503 - c.1580), y el lienzo que con un tema similar ejecutó Velázquez: Encuentro de San Antonio Abad con San Pablo, primer ermitaño (Madrid, Museo Nacional del Prado, c.1634, 261 x 192,5 cm).

\section{METODOLOGÍA}

Esta última pintura se caracteriza por una pincelada y una técnica tan suelta y natural que antaño se tenía por una de sus últimas obras (Gállego, 1990, p. 284) (fig. 1). Brown y Elliot (1981-2003, pp. 209-213), aclararon las circunstancias que rodearon su realización. Cuando el conde-duque de Olivares ordenó edificar el complejo palaciego del Buen Retiro para Felipe IV dispuso, diseminadas en sus jardines, siete ermitas, cuya construcción - como casitas de ladrillo y piedra-, finalizó en 1636. Cada una de ellas contaba con una reducida capilla con altares, pinturas y esculturas ${ }^{1}$. El cuadro de Velázquez fue pintado para la dedicada a San Pablo Ermitaño ${ }^{2}$. No se ha encontrado documento que pruebe su autoría, pero así lo establecieron, desde primera hora, tanto Antonio Ponz (1792, p. 108), Piquer (Bejís, 1725 - Madrid, 1792), como Juan Agustín Ceán (1800, p. 178) Bermúdez (Gijón, 1749 - Madrid, 1829). Al poco tiempo de su realización aparecía colocada en la vecina ermita de San Antonio,

1 Las ermitas fueron dedicadas a San Juan Evangelista, Santa María Magdalena, San Isidro, San Jerónimo, San Bruno, San Pablo y, por último, a San Antonio de Padua o de los Portugueses. Eran habitadas y atendidas, cada una de ellas, por un fraile de San Jerónimo. Vid. Rodríguez, 2009-2010, pp. 136 y 140.

2 Fue construida entre 1632 y 1633 por Juan de Aguilar y Alfonso de Carbonel. En marzo del último año finalizaron los pagos al escultor italiano Juan Antonio Ceroni por una estatua de piedra de San Pablo ermitaño que había de colocar en la fachada de la ermita, así como por ocuparse del retablo del interior, dorado por Miguel de Viveros, vid. Rodríguez, 2009-2010, p. 142. En varios casos, estaban decoradas con esculturas clásicas y pinturas mitológicas. 


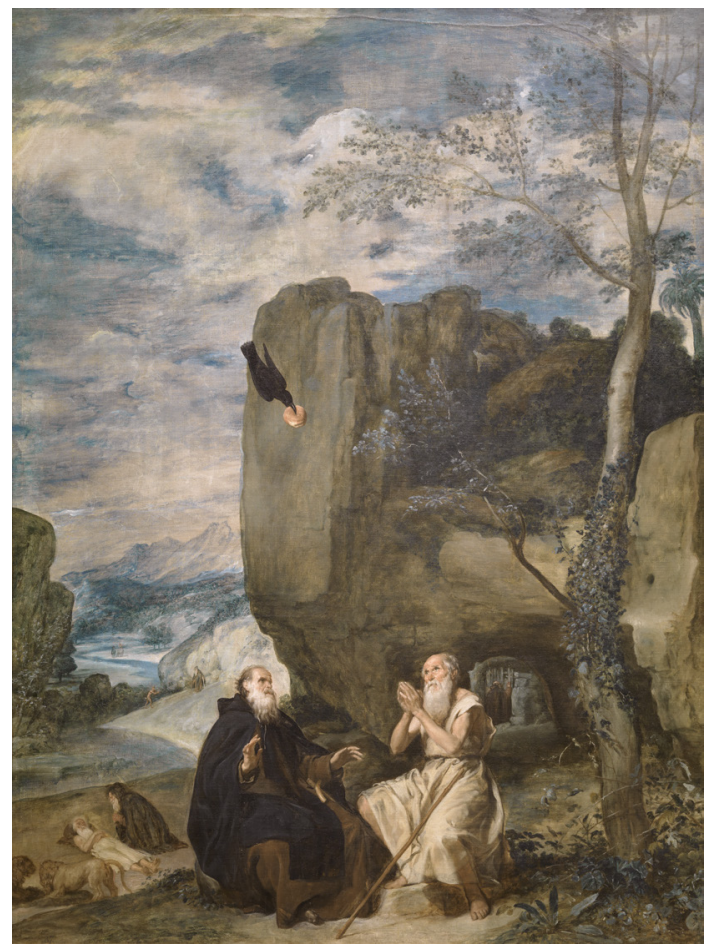

Fig. 1. Diego Rodríguez de Silva y Velázquez, Encuentro de San Antonio Abad con San Pablo, primer ermitaño, c.1634, óleo sobre lienzo. 261 x 192,5 cm, Madrid, Museo Nacional del Prado, P001169.

por estar la de San Pablo en obras, desacralizada y sin uso religioso (Gállego, 1990, p. 288) $)^{3}$.

En relación con el proceso creativo del lienzo, Rodríguez (2009-2010, p. 145) supone sería Francisco de Rioja (Sevilla, 1583 - Madrid, 1659), bibliotecario real y amigo desde la juventud de Velázquez, el que pondría en las manos del pintor la fuente de la que servirse para conformar la historia representada: no la Vida de San Antonio abad, escrita por su contemporáneo San Atanasio de Alejandría (296 - 373), ni la Vida de San Jerónimo, sino La leyenda dorada de Jacobo de la Vorágine (Varazze, 1230 - Génova, 1298), en la edición castellana editada en 1569 por el impresor sevillano Juan Gutiérrez. Sin embargo, el mismo investigador, siguiendo a Angulo (1947-1999, pp. 53-64), cree que antes que la referencia literaria, Velázquez tuvo pre-

3 Rodríguez, 2009-2010, p. 142, cree que estas ermitas no respondían al tipo de las dedicadas a los anacoretas, tampoco las de devoción popular situadas en las salidas de las poblaciones, con imágenes y santos, sino que eran escenario de la fiesta cortesana, utilizadas por los miembros de la familia real cuando iban en peregrinación a ellas en los días indicados de las festividades. La de San Pablo estuvo desacralizada entre 1659 y 1667, formando parte de una fachada o palco desde el que apreciar las representaciones teatrales. 
sente a la hora de ejecutar la obra su propia cultura visual, es decir, tanto la xilografía de Alberto Durero (Núremberg, 1471 - 1528), realizada en 1504, para los personajes, como la pintura de Joachim Patinir (Dinant, c.1480 - Amberes, 1524), para el paisaje

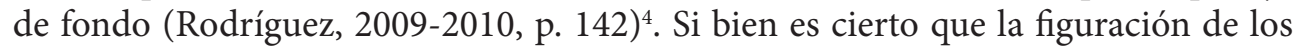
santos es bastante análoga entre Durero y Velázquez, el asunto del paisaje es más complejo, ya que no se trataba solo de la plasmación de un exterior que ofreciese marco idóneo a la acción, sino de un escenario que debía articular toda la historia narrada en La leyenda dorada como una de las más bellas y complicadas que jalonan la tradición del monacato primitivo.

De hecho, Angulo (1947-1999, p. 58) estableció que Velázquez había metamorfoseado los árboles de Patinir en rocas, mientras que Brown (1986, p. 97) aludía a la influencia que pudieron tener los frescos de la Villa Sachetti en Castelfusano, realizados por Pietro da Cortona (1596 - Roma, 1669). De la misma manera, Rodríguez (20092010, p. 146) cree que el paisaje del sevillano es más idílico que el de Durero, tal y como podían ser los jardines del Buen Retiro en los que se integraba la ermita que acogía esta pintura ${ }^{5}$. Lo que le lleva a esta creencia es la circunstancia de que la pintura sea posterior a la vuelta del primero de sus viajes italianos (1629-1631), en el que había aprendido de las soluciones y modelos de los Carracci y de otros integrantes de la escuela boloñesa que aun tendría muy presente para el momento de realización de esta obra ${ }^{6}$. Gállego (1990, p. 289) pone en cuestión los intentos por fijar la procedencia de la inspiración paisajística, pero él mismo propone, además de las referencias de Cortona y Gaspard Dughet (Roma, 1615 - 1675), las que pudo apreciar el pintor sevillano en el Casino Ludovisi de Giovanni Francesco Barbieri, Il Guercino (Cento, 1591 - Bolonia, 1666) ${ }^{7}$.

\section{DISGUSIÓN Y RESULTADOS}

Particularmente pienso que todas estas relaciones no son sino interesantes ejercicios de erudición que demuestran, por un lado la perfecta adecuación de esta obra a su contexto artístico, pero que a la vez evidencian la tendencia de la historiografía a establecer líneas de conexión, que si bien son plausibles y evidentes respecto a lo formal, muchas veces resultan demasiado débiles al no estar respaldadas con firmeza, contribuyendo, en ocasiones, a enmarañar la comprensión del alcance de la cultura visual como fundamento del acto creativo, pero que no apuntan, en este caso, con dirección inequívoca al verdadero arranque de la inspiración velazqueña: el cuadro

4 Ambas fuentes visuales fueron accesibles para Velázquez en las colecciones y sitios reales.

5 Rodríguez, 2009-2010, p. 148 cree que debe ser desechada la inspiración de la morfología rocosa de la llamada ciudad encantada de los alrededores de Cuenca que propusiera Campo, 1983.

6 Rodríguez, 2009-2010, p. 148, cree que quizá pudo inspirarse en el paisaje que aparece en la Asunción de la Magdalena que realizara en 1618 Giovanni Lanfranco (Parma, 1582 - Roma, 1647).

7 Gállego, 1990, p. 289: "Nada hay más fácil (y, en general, más inútil), que basar la genialidad de una obra de arte en los precedentes que proliferan en cuanto se contempla el tema, con lo que, creyendo que existe tan alto número de precedentes, que no hay nada de Velázquez". 
del mismo tema de Pedro de Campaña, mencionado con anterioridad. Que la correspondencia entre una y otra obra es clara se ha apuntado ya por parte de la historiografía (Angulo, 1951, pp. 29 y 30; Serrera, 1999, p. 54 y J.M.S. y L.M.R., 1999, pp. 22 y 23), pero, según mi parecer, los pocos estudios que repararon en ello, persiguieron antes explicar el proceso intelectual de conformación del cuadro velazqueño -con el rastreo de las fuentes grabadas utilizadas por su autor-, que situarlo como una solución idónea a la que pudo recurrir el sevillano cuando fue necesario.

La obra del flamenco supone un hito en su producción y debería encuadrarse en su primer periodo, el de la pervivencia de la expresividad de raíz gótica (fig. 2). Aparece firmada -"hoc opus faciebat Petrus Campaniensis natione braba(ntia)" - (fig. 3), y rematada en medio punto. Formaría parte de un retablo donde sería la pieza central y que habría sido completado por otras dos tablas pequeñas en los laterales. Dicho retablo fue reformado en 1681. En esa ocasión, fueron suprimidas las pinturas lindantes, quedando la central como pieza única dentro de un nuevo retablo de modesta estructura (fig. 4). En el banco aparece la inscripción "Esta capilla, altar, retablo y entierro es de Doña María de Herrera Franco, de sus descendientes, herederos y sucesores. Renovóse este año de MDCLXXXI" (Valdivieso, 2008, pp. 77-79) ${ }^{8}$. Este retablo fue situado por Ceán Bermúdez (1800, p. 203) en el altar del baptisterio, es decir, a los pies del templo, donde se ubicó hasta la reforma que sufrió la iglesia en 1995, fecha en que se instaló en el arranque del muro de la nave de la Epístola. Iconográficamente, se muestran los antecedentes y circunstancias posteriores acontecidas con motivo de la visita de San Antonio Abad a San Pablo Ermitaño, con el episodio del cuervo panadero en primer término. Para ello, Campaña recurrió a "figuras anchurosas y monumentales" (Valdivieso, 2008, p. 78)9 , calificadas por Angulo (1951, p. 29) como "prerrubenianas", que muestran cierta rudeza en su expresión corporal, aumentada por la emotividad desarrollada de sus rostros, tensos y anhelantes, sobre todo el de San Pablo, que muestra sus ojos desvinculados y su boca entreabierta -como hará Zurbarán en el siglo siguiente-, permite apreciar la dentadura sucia y deteriorada y las encías contraídas, algo que redunda en el riguroso realismo flamenco de su autor $^{10}$. Con respecto al color, como analiza Valdivieso (2008, p. 78), son sobrios los

8 El año de ejecución se desprende de la información facilitada por un contrato realizado entre Pedro de Campaña y María Niño en 1546 para realizar un retablo particular en el convento de la Victoria de Triana. En ese documento se expresa que las pinturas habían de ser realizadas como las que había hecho Campaña en la parroquia de San Isidoro para el mercader Cristóbal Ruiz. Por consiguiente, la pintura de los santos ermitaños hubo de realizarse con anterioridad, en c.1545 como cree Valdivieso (2008, pp. 77-79).

9 En Velázquez perderán referencia a favor del paisaje, como ocurre en la pintura de staffage.

10 Este detalle ha suscitado cierta polémica, ya que no casa con la experiencia vivida por Campaña en Italia, país del que, se creía, llevó formas y maneras a Sevilla, ciudad a la que llegó, por tanto, con su flamenquismo atenuado. Para J.M.S. y L.M.R., 1999, p. 22, el pintor no pudo superar en el país transalpino su formación juvenil, ya que no permaneció allí mucho tiempo. Sería en la ciudad del Guadalquivir donde evolucionaría a las formas italianas. Valdivieso, 2008, pp. 28, 31 y 35, zanja el asunto con el establecimiento de las dos etapas de su producción: el primer periodo, hasta 1550, sería el de las profundas reminiscencias nórdicas, y posteriormente, el segundo, entre esa fecha y 1562, el de formas 


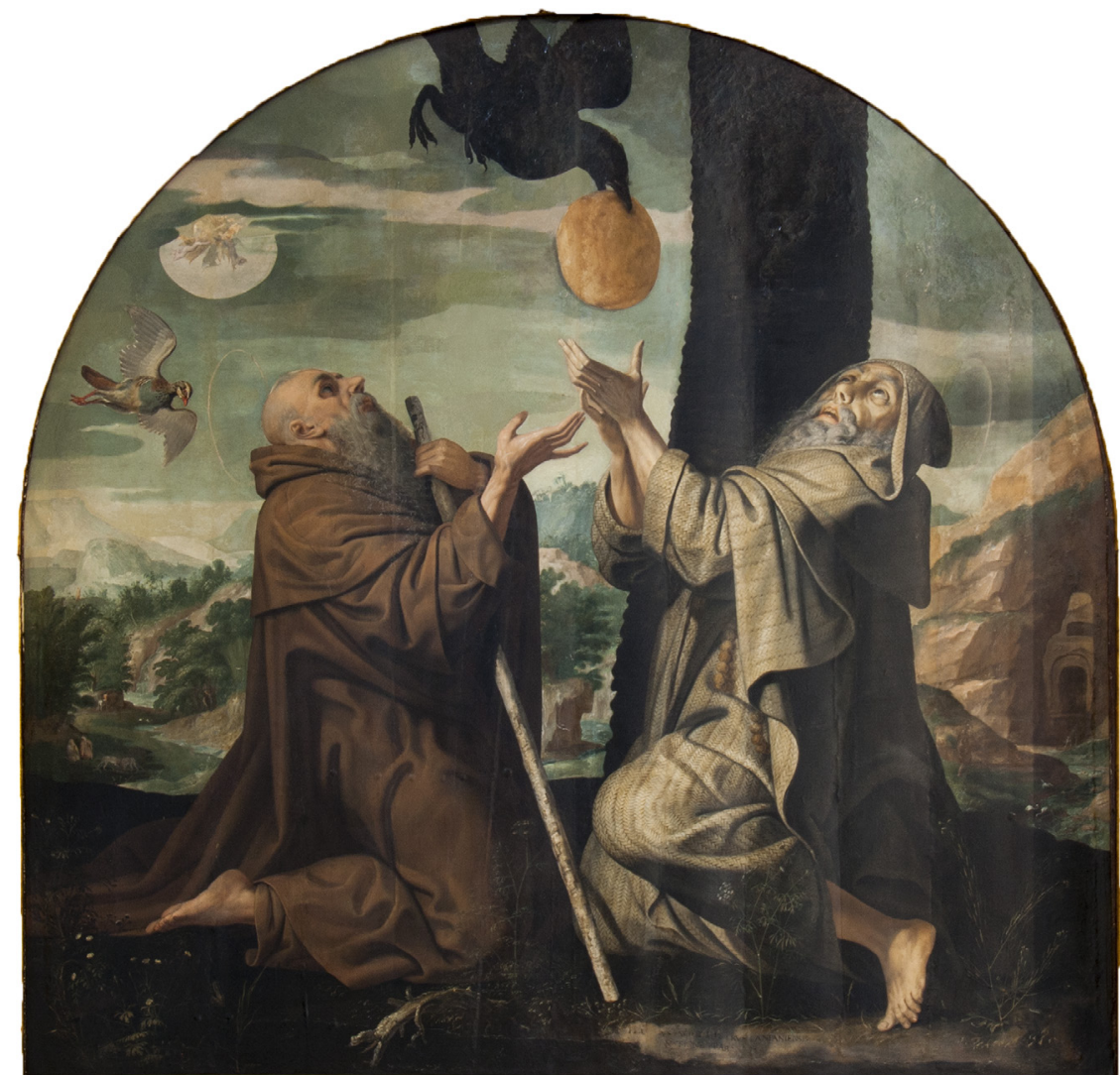

Fig. 2. Pedro de Campaña, San Pablo Ermitaño y San Antonio, c.1545, óleo sobre tabla. 221 x $231 \mathrm{~cm}$, Sevilla, parroquia de San Isidoro.

tonos marrones y grises dispuestos en las túnicas y mantos de los dos santos, amortiguados por los matices verdes y azules del fondo del paisaje.

La calidad y admiración suscitadas por Campaña en el panorama del Renacimiento español fue enorme, ya desde finales del quinientos. Precisamente, Francisco Pacheco (Sanlúcar de Barrameda, 1564 - Sevilla, 1644), maestro y suegro de Velázquez, lo apreciaba sobremanera, ya que lo calificó de "sujeto más que humano" (Pachecho, 1599-1985, p. 293), dedicándole versos laudatorios, seguidos por otros de Jerónimo González de Villanueva, caballero veinticuatro de Sevilla y tesorero de la

más mediterráneas. Por estilo era un pintor flamenco puro, pero tras mediar la centuria -momento en que Luis de Vargas (Sevilla, c.1505 - 1567), introdujo un marcado culto estético italiano en Sevilla-, evolucionó Campaña a algo parecido, tal y como puede apreciarse en algunas pinturas del retablo que realizó para la parroquia de Santa Ana, incluso en las del retablo de la Purificación de la capilla del mariscal de la Catedral. Todo, según este último investigador, para gustar a una clientela poco habituada a la expresividad en pintura y que venía acostumbrada a la tradición de Alejo Fernández (Córdoba, c.1475 - 1545), solemne y enfático, pero parco en franqueza formal. 
Casa de la Moneda. Este autor introduce una noción muy destacada con sus versos: "pero más gloria alcanza y más segura / quien te hurtó a las sombras del olvido, / pues vivirás eterno en su pintura"; y "Si el gran Pacheco, en línea verdadera, / viendo que huye arrebatadamente / al olvido tu nombre..., señalando en ambos casos al veedor de pinturas del Santo Oficio como recuperador y recreador de la pintura del artista nórdico casi medio siglo después de su marcha de la ciudad del Guadalquivir. Esta posición prueba que Pacheco, que habría querido resucitar la pintura de Campaña, por significar para él un perfecto vehículo de influencia italiana, trasladó ese afán a su discípulo Velázquez (Marías, 2019, pp. 265-284), algo que ratifica Serrera (1999, p. 54): "Campaña, muy celebrado por su suegro, fue uno de los pintores que más estudió Velázquez, como pone de relieve la relación que se puede establecer entre algunas obras de estos dos maestros", tales como las pinturas del retablo del Mariscal -debidas a Campaña-, para su Imposición de la casulla a San Ildefonso (Sevilla, Centro Velázquez de la Fundación Focus Abengoa, c.1623), o para la conformación del carácter de La venerable madre Jerónima de la Fuente (Madrid, Museo Nacional del Prado, 1620 $)^{11}$. Como añadido a lo anterior, otra de las razones por las que Pacheco establecía la conexión entre Campaña, su propia pintura, y por ende, la de su discípulo Velázquez, es consecuencia de su convicción vasariana: la pintura para él es resultado ineludible de un sumatorio de experiencias protagonizadas por los pintores precedentes, reconocidos y consagrados por su contribución y prestigio. Por tanto, no se trata de una virtud de gusto de Pacheco, sino de una cuestión de convicciones artísticas el hecho de apreciar -sea como sea-, a los maestros que le han precedido en la práctica de la pintura. De este modo, asumir a Campaña es, al mismo tiempo, asumir la secuencia de calidad de la pintura sevillana ${ }^{12}$.

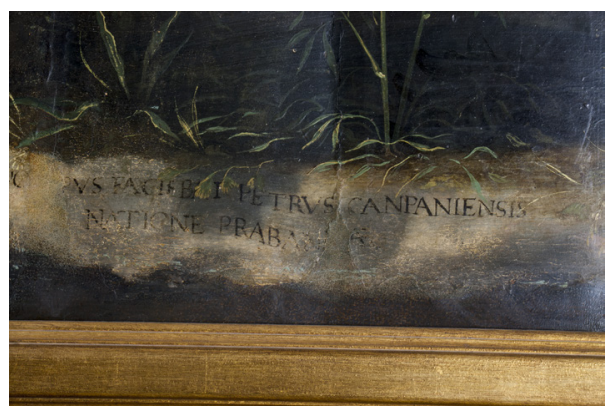

Fig. 3. Pedro de Campaña, San Pablo Ermitaño y San Antonio, c. 1545, óleo sobre tabla. $221 \times 231 \mathrm{~cm}$, Sevilla, parroquia de San Isidoro. Detalle.

11 Además de estas, obras flamencas de otros autores también pudieron ejercer un "influjo directo" sobre Velázquez, tales como el retablo (c.1530-1540), dedicado a Santa Catalina pintado por Jan van Hemessen para la capilla de los caballeros Alfaro y Bravo de Lagunas en la parroquia de San Vicente. Cfr. Morales, 1999, p. 18.

12 Agradezco esta y otras consideraciones al Prof. Dr. Pedro M. Martínez Lara. 
Quizá se pensara que la deuda de Velázquez con Campaña se mantendría vigente durante la etapa sevillana, mientras que posteriormente habría tenido otras referencias. Sin embargo, creo que en un momento en que era tan determinante la cultura visual, Velázquez, al igual que otros artistas, seguía atendiendo las necesidades de la corte -al menos unos diez o quince años después de abandonar Sevilla-, con los referentes aprendidos en su juventud, no solo pertenecientes al campo de la pintura, sino a otros como el de la escultura. Así, como creyó Gómez Piñol, parece probarlo el patrón que pudo guiar a Velázquez a la hora de realizar una obra cercana en el tiempo a la de los santos anacoretas: el Cristo crucificado (Madrid, Museo Nacional del Prado, c.1632), consumado con la reminiscencia presente del Cristo de San Agustín de Sevilla, una talla del siglo XIV derivada del Cristo de Burgos, que fue destruida en 1936, pero que llegó a ser durante la Edad Moderna la gran devoción popular de la ciudad y que, con mucha probabilidad, sería una permanente presencia en la vida religiosa del Velázquez de la etapa hispalense ${ }^{13}$.

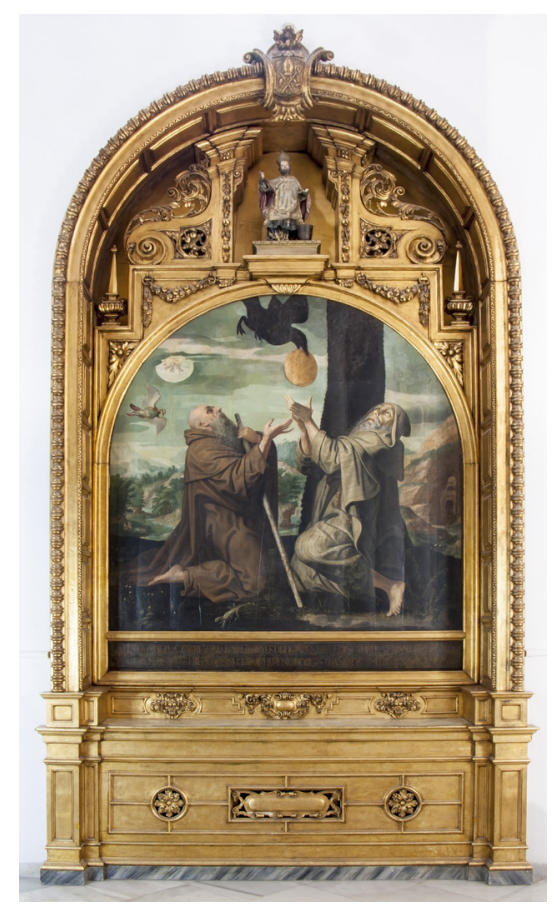

Fig. 4. Pedro de Campaña, San Pablo Ermitaño y San Antonio, c.1545, óleo sobre tabla. 221 x $231 \mathrm{~cm}$, Sevilla, parroquia de San Isidoro. Visión general con retablo.

13 Al fin y al cabo "cualquier aproximación al periodo sevillano de Velázquez debe realizarse por una vía indirecta, la del contraste con el medio artístico y cultural en el que se desenvolvió su juventud", cfr. Lleó, 1999, p. 74. Como Gómez Piñol, Pereda, 2017, p. 425, sospecha que el Crucificado de Velázquez toma el modelo de un exvoto como los que proliferaban del Cristo de Burgos. 
Con estos presupuestos, por tanto, no sería descabellado pensar que, cuando le fue encargado el lienzo para la ermita del Buen Retiro, Velázquez volviera a recurrir a su imaginario sevillano para el término de una obra que contiene un paisaje calificado como uno de los mejores de toda la escuela española (así lo cree tanto Gállego, 1990, p. 290 como Rodríguez, 2009-2010, p. 146) ${ }^{14}$. Y precisamente en el análisis del paisaje es donde mejor se unen los lazos entre Campaña y Velázquez. La clave la da lo representado en miniatura y en distintos planos insertos en el mismo (fig. 5). Por un lado, San Antonio Abad (Heracleópolis Magna, 251 - Monte Colzim, 356), fundador de la tradición monacal cristiana, vagaba penitente, como otros compañeros, por los desiertos de Egipto y Tebaida, convertidos con su presencia y sacrificio en "jardines apacibles y deleitosos"15. Este santo tenía bastante experiencia a la hora de ahuyentar las bestias salvajes que salían a su encuentro en el campo. Estas no eran otra cosa que las formas convencionales que adoptaban las criaturas infernales que trabajaban para desviarlo de su camino. San Antonio tenía noventa años (aun viviría ciento cinco), cuando salió en busca de un siervo de Dios del que desconocía el nombre. El primer día de camino se encontró un monstruo medio hombre medio caballo, un hipocentauro, al que le preguntó dónde estaba aquel al que buscaba. La bestia le señaló el camino y San Antonio marchó por allí. Dentro de un profundo valle vio otro monstruo, el fauno, que le indicó por dónde seguir, y llegó al desierto. El tercer día se encontró con la loba fatigada de sed y siguiéndola llegó hasta una cueva. El objetivo de su búsqueda no era otro que San Pablo, llamado el primer ermitaño de la cristiandad, o también de Tebas o el Egipcio, por su procedencia (228 - 342). Y allí se encontró con él (Vorágine, 2008, p. 176).

La leyenda dorada no ofrece más datos que estos, por lo que es necesario conocer más detalles en la "Vida de San Pablo Primer Eremita", incluida en la hagiografía Vita Sancti Pauli primi eremitae, escrita en la segunda mitad del siglo IV por San Jerónimo (Estridón, 342 - Belén, 420), quien ofrece varios lugares comunes a la hora de describir las vicisitudes de todos estos padres del desierto ${ }^{16}$. El padre de la Iglesia describe cómo, de adolescente, San Pablo se llegó a internar en el desierto huyendo de circunstancias familiares, hasta alcanzar una cueva que había estado dedicada, tiempo ha, a la acuñación de moneda durante el romance y alianza entre Marco Antonio (Roma, 83 a.C. - Alejandría, 30 a.C.) y Cleopatra (Alejandría, 69 a.C. - 30 a.C.). Junto a la cueva existía una vieja palmera con ramas entrecruzadas, que sería la que, durante toda su vida, le procuraría vestido y alimento. Entonces, ciento trece años más tarde, fue cuando se produjo el encuentro con San Antonio Abad. Primero se encontró con el hipocentauro, que le indicó el camino a seguir, pero no al día siguiente,

14 Tiene un "valor de signo" para Vilar, 1963, p. 60.

15 San Atanasio de Alejandría: Vida de San Antonio Abad, p. 166. [en línea], <http://www.documentacatholicaomnia.eu/03d/0295-0373,_Athanasius,_Vida_de_San_Antonio_Abad,_ES.pdf> [Consulta: 23 de julio de 2018].

16 Sigo la edición alojada [en línea], <http://paulinosdeyuste.es/49,Vita-Sancti-Pauli-Primi-Eremitae $>$ [Consulta: 25 de julio de 2018]. 


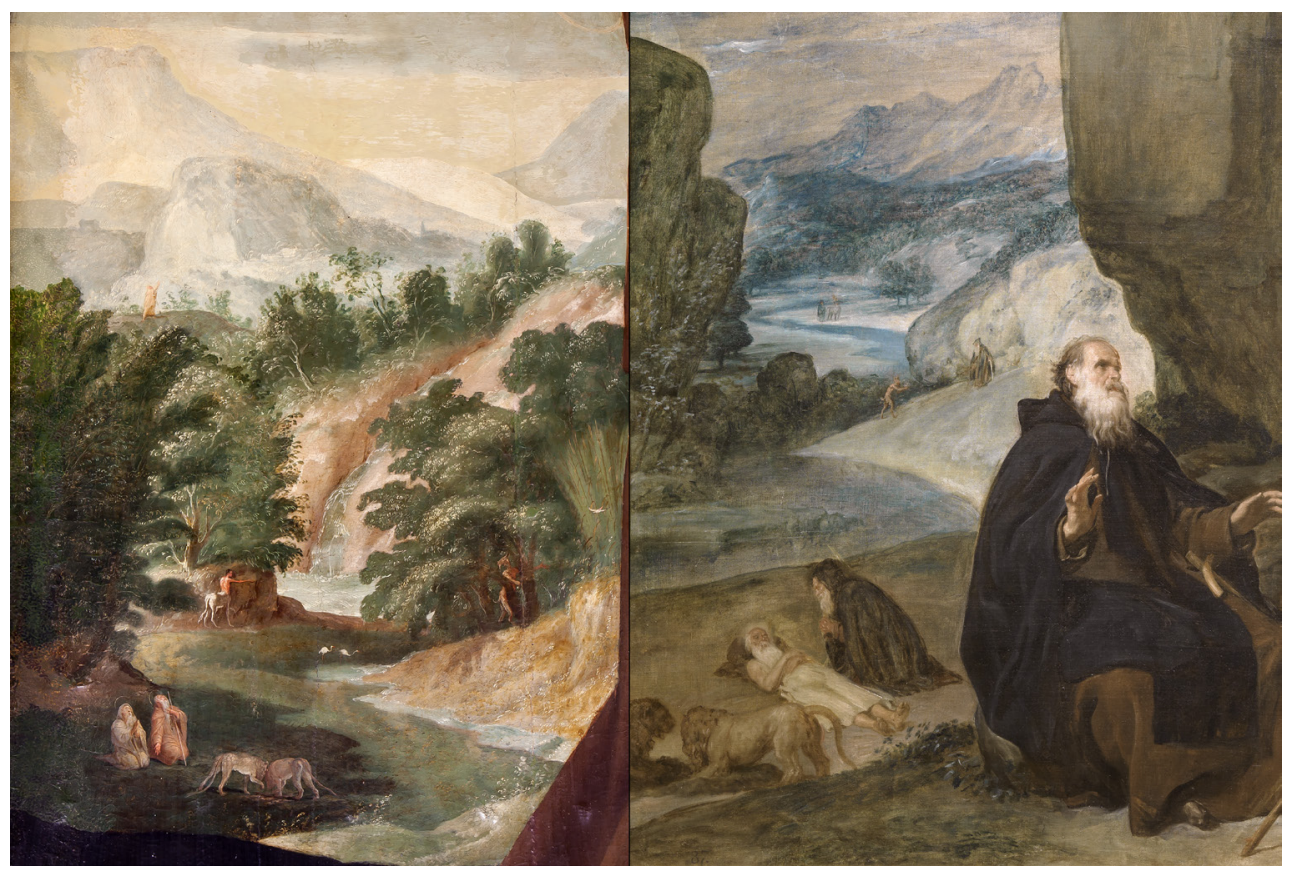

Fig. 5. Pedro de Campaña, San Pablo Ermitaño y San Antonio, c.1545, óleo sobre tabla. 221 x 231 cm, Sevilla, parroquia de San Isidoro; y Diego Rodríguez de Silva y Velázquez, Encuentro de San Antonio Abad con San Pablo, primer ermitaño, c.1634, óleo sobre lienzo. 261 x 192,5 cm, Madrid, Museo Nacional del Prado, P001169. Comparativa de ambos paisajes.

sino tan solo un rato más tarde "vio en un valle rocoso a un hombrecillo pequeño, con la nariz chata y cuernos en la frente, y la última parte de su cuerpo terminada en pies de cabra", que le ofreció unos dátiles para el sustento de su camino. Cuando el santo le preguntó quién era, el curioso personaje le dijo "Yo soy un mortal, uno de los moradores del yermo que los paganos, engañados por sus muchos errores, honra con los nombres de sátiro, fauno y pesadilla", antes de pedirle que rogara a Dios por él y su comunidad. San Antonio, esperanzado, siguió su camino. Al amanecer de la tercera jornada "vio de cerca, entre las sombras, una loba que corría jadeante de sed hacia las estribaciones de un monte. Y clavando en ella sus ojos vio allí cerca una cueva. $\mathrm{Al}$ irse la loba, Antonio se acercó y comenzó a mirar hacia adentro, más la oscuridad reinante no le permitió satisfacer su curiosidad", por lo que hubo de entrar en la cueva sigilosamente. A pesar de ello, San Pablo notó su presencia y se encerró en su celda con una traba. San Antonio se arrodilló delante de la estancia y le rogó durante horas que le admitiera, o por lo menos, que le dejara verlo. Tras horas de súplicas, San Pablo abrió la puerta y ambos se abrazaron llamándose por sus nombres, para, a continuación, dar gracias a Dios. Después salieron al exterior y mientras San Antonio 
contaba a San Pablo todas las vicisitudes de los tiempos que corrían en relación con la religión y el temor a Dios, "de pronto vieron un cuervo que se había sentado sobre una rama del árbol; y deslizándose desde allí con suave vuelo, les dejó un pan entero ante sus miradas asombradas, y se fue. Entonces dijo Pablo: 'Mira, Antonio, el Señor, nos ha enviado la cena, verdaderamente es piadoso y misericordioso. Hace sesenta años que me envía cada día medio pan; mas ahora, por haber venido tú, Cristo ha duplicado la ración a sus soldados"'. Se alimentaron ambos y, al día siguiente, San Pablo manifestó a San Antonio que ya había vivido muchos años de servicio a Dios y que su muerte era próxima. Su llegada no significaba otra cosa que el cumplimiento santo del enterramiento. San Antonio se entristeció sobremanera, y para evitar aumentar su sufrimiento viéndole morir, San Pablo le pidió le trajera la capa de Atanasio, obispo de Alejandría, para cubrir su cuerpo. Volvió entonces San Antonio a su convento por la prenda y cuando caminaba de vuelta a la cueva "vio subir a Pablo entre la multitud de los ángeles y entre los coros de los Profetas y Apóstoles, resplandeciendo con una blancura de nieve". Su cuerpo lo encontró "hincado de rodillas, la frente alzada y las manos extendidas al cielo, exánime. Como en un primer momento le pareció que aún vivía y rezaba, se puso también él a orar". Después, teniendo por cierto que había muerto, envolvió el cuerpo, lo sacó fuera de la cueva y cantó himnos y salmos en su honor. Dispuesto a enterrarlo, comprobó que no tenía azada para hacerlo, pero, mientras pensaba estas cosas aparecieron dos leones corriendo por el desierto en su dirección. Estos se dispusieron alrededor del cuerpo de San Pablo y lo lloraron, para, a continuación, cavar con sus garras la tierra hasta ahuecarla con objeto de guardar allí el cuerpo del santo. San Antonio los despidió con su bendición, cargó el cuerpo, lo introdujo en el hueco, echó tierra encima y levantó un montículo. Después, recogiendo la túnica que San Pablo se había fabricado con las hojas de la palmera que presidía aquel ámbito, volvió a su convento que estaba a cuatro días de viaje y narró toda la historia a sus compañeros ${ }^{17}$.

Todo este imaginario literario se aprecia de manera magistral en el lienzo de Velázquez, que se apoya en la simultaneidad de planos en función del avance de San Antonio en pos de la cueva de San Pablo. Así, en miniatura pueden apreciarse las equivalencias de las jornadas de camino del santo con las escenas representadas: en el extremo de lontananza del paisaje cómo aquel se encuentra con el centauro junto a un riachuelo, y cómo, tan solo un plano más adelante, hace lo mismo con el sátiro, que se aproxima a él subiendo un colina. Rodríguez (2009-2010, p. 148) cree que Velázquez no pinta el tercer encuentro, el de la loba, pero Gállego (1990, p. 290) cree que "una mancha informe en el río pudiera ser el lobo (sic)". La tercera escena de la pintura se ubica en el fondo de la zona derecha y muestra cómo San Antonio, de rodillas junto a la puerta de la cueva, suplica al primer ermitaño que le deje entrar para

17 Toda la narración y las citas han sido extraídas de la "Vida de San Pablo Primer Eremita” escrita por San Jerónimo, alojada [en línea], Vita Sancti Pauli Primi Eremitae, s/p. de http:// paulinosdeyuste.es/49,Vita-Sancti-Pauli-Primi-Eremitae [Consulta: el 20 de enero de 2019]. 
reunirse con él. La cuarta escena en la secuencia de los hechos es la principal, situada en el centro de la composición: los santos dan gracias a Dios cuando ven descender en picado hacia ellos el cuervo con una pieza entera de pan en su pico para alimentarlos. La quinta y última escena es la que aparece en el ángulo inferior izquierdo: San Antonio llorando el cadáver de San Pablo mientras dos leones excavan su tumba.

Esto que parecía una traducción pictórica perfecta y complejamente hagiográfica por parte de Velázquez -que habría estudiado a conciencia las fuentes de la Vorágine y de los relatos recogidos por San Atanasio y San Jerónimo-, no es más que la versión sublimada en lo estético y espiritual -"con ojos modernos, a través de la luz" (Gállego, 1990, p. 290)-, de la solución adoptada por Campaña en su tabla de la parroquia sevillana de San Isidoro. El por qué no se había establecido este hecho de manera inequívoca se debe a algo muy prosaico: el fondo del lienzo de Campaña estuvo recubierto "por humo y polvo" hasta la restauración practicada a la pintura en el Instituto Andaluz del Patrimonio Histórico en 1998 (Baceiredo y López, 1997, pp. 21-29). Con anterioridad era imposible que se apreciaran los detalles del paisaje. El primer análisis de la tabla restaurada no tuvo lugar hasta la aparición de la monografía que dedicó Valdivieso (2008, p. 78) a Campaña, donde escribe: "El paisaje que se desarrolla al fondo es igualmente de inspiración flamenca y sirve para que en él, con pequeñas figuras, se narren distintos pormenores acontecidos antes y después de la visita de San Antonio a San Pablo. En principio se advierte que estas pequeñas figuras están realizadas con cierto descuido y escasa aplicación artística; se puede identificar en ellas al centauro, que enseñó el camino a San Antonio para encontrar a San Pablo, al sátiro que aquel se encontró en su tránsito y al lobo que finalmente le guió hasta el ermitaño. Igualmente en este paisaje se describen los episodios que sucedieron después de la despedida de ambos, ya que San Antonio, en su viaje de regreso, pudo ver cómo unos ángeles subían al cielo el alma de San Pablo, lo que le hizo comprender que había muerto. Este detalle había permanecido repintado durante siglos y no se ha podido observar hasta la restauración de la pintura efectuada en 1998. También aparece San Pablo arrodillado, muerto junto a San Antonio, quien contempla cómo dos leones cavan la tumba del ermitaño fallecido". Los textos que analizaron la relación entre Campaña y Velázquez, publicados por Serrera y Méndez con ocasión de las celebraciones del IV centenario velazqueño, se escribieron con la tabla aun sin restaurar, muda por tanto en cuanto a los detalles del paisaje ${ }^{18}$. Por ello, aunque la

18 Serrera, 1999, p. 54; y J.M.S. y L.M.R., 1999, pp. 22 y 23, aprovecharon los textos que habían publicado en inglés para Velázquez in Seville en Davies, Harris y Clarke, 1996, muestra que suscitó el siguiente comentario: "Cualquiera que viese la exposición o incluso que haya leído el catálogo habrá podido comprobar que suscita más problemas de los que resuelve. Como suele acontecer con Velázquez, al deslumbramiento inicial sucede un creciente sentimiento de frustración; como si el artista nos mantuviese discretamente a raya, como si se escapase de nuestros interrogantes con esa reticente flema que llegaba a exasperar al propio Felipe IV", cfr. Lleó, 1999, p. 73. 
reminiscencia era patente ${ }^{19}$, las similitudes aun tenían que dilucidarse. Otro detalle que parece corroborar la dependencia velazqueña de la tabla de Campaña es que la del sevillano fue ideada para rematarse en semicírculo (como se aprecia claramente), al igual que le ocurre a la del flamenco ${ }^{20}$.

Es evidente que donde se hallan similitudes también se encuentran diferencias y en ese terreno se pueden señalar el dispar tratamiento corporal que elige Velázquez frente a Campaña a la hora de representar los santos ermitaños, así como la atmósfera y el aire que lo envuelve todo con tibieza y serena luminosidad, así como la eliminación de determinados detalles naturalistas, de destacable valentía para la pintura de Campaña, pero exógenos a la obra del sevillano en su etapa de la corte ${ }^{21}$.

Por todo lo anterior, podría establecerse que a la hora de conformar el cuadro de los ermitaños, Velázquez no tomó las referencias literarias quizá facilitadas por Rioja, como cree Rodríguez (2009-2010, p. 145), ya que el texto de la Vorágine es, con respecto a la narración de este episodio, sucinto y poco concreto, sino que, de haberlas tomado, hubo de completarlas recurriendo a su cultura visual: como descubrió Angulo (1947-1999, pp. 53-64), Durero y Patinir para plantear el paisaje y la ubicación de las figuras de los santos, sin duda, pero fue necesario tomar la referencia de la pintura del mismo tema de Campaña para insertar la narración del camino de búsqueda de San Antonio con miniaturas en distintos planos. Este sí parece el artista que, bien por iniciativa propia o por indicación de sus comitentes, ofreció el mejor reflejo de los textos hagiográficos, sobre todo del de San Jerónimo, en el fondo de su paisaje. Por lo tanto, ni las referencias de Pietro Da Cortona, Lanfranco, Dughet, Il Guercino o los espacios naturales de Cuenca o del Buen Retiro, como apuntaron varios autores (Brown, 1986, p. 97; Gállego, 1990, p. 284; y Rodríguez, 2009-2010, p. 148), sino el que había apreciado durante su juventud y periodo formativo en Sevilla, de la mano de su maestro Pacheco, fervoroso seguidor de la estética de Campaña, fue el que le facilitó la tarea de finalizar con éxito su pintura para el Buen Retiro. Esta posibilidad ya fue apuntada por Angulo (1951, p. 30), Serrera y Méndez (1999, pp. 22 y 23), pero estos investigadores no exploraron las auténticas dependencias del cuadro velazqueño con respecto al del nórdico, por no poder apreciar el paisaje en toda su plenitud, repintado y ennegrecido hasta la restauración de 1998. Solo a partir de

19 Angulo, 1951, p. 30 acierta con su fina expresión: "lo grabado que este fondo de Campaña quedó en la memoria del príncipe de nuestros pintores".

20 Es posible que perdurase esta tradición con respecto al formato empleado para la representación pictórica de este asunto, ya que, además de las dos obras mencionadas sobre los primeros ermitaños, la que muestra el mismo pasaje en el trascoro de la Catedral de Burgos también está rematada en semicírculo. La de Velázquez se amplió a su actual dimensión rectangular, vid. Gállego, 1990, p. 290.

21 Me refiero a la perdiz que aparece volando en la zona izquierda del cuadro de Pedro de Campaña, un detalle naturalista para Valdivieso, 2008, p. 78, pero es posible que, en la lógica de San Jerónimo, quien habla de que el santo, una vez falleció, "parecía volar como un pájaro", haga referencia al alma de San Pablo ermitaño, camino del cielo, para transfigurarse, en secuencia inmediata, con la luna al entrar en la bóveda celeste. No es baladí recordar la vigencia de la creencia altomedieval cristiana sobre que las almas de los difuntos se congregaban en el lado oculto de la luna. 
entonces puede percibirse cómo en Velázquez la primera formación es la que pervive con mayor fuerza, incluso una década después de su llegada a la corte madrileña ${ }^{22}$. Este fenómeno es natural y frecuente: le ocurrió al mismo Campaña, que continuaba pintando con estética marcadamente nórdica a su llegada a Sevilla procedente de Italia. Desde luego que en la obra de Velázquez se perciben varias metamorfosis a lo largo de su carrera, sobre todo en los años subsecuentes a sus viajes a Italia, pero en la primera década de permanencia en la corte pintaba con una estética adecuada como para ser llamado y conocido por el apodo de "el sevillano". Las raíces hispalenses de Velázquez son perdurables y evidentes en su obra posterior, y parece diáfano que Campaña fuera su mayor referente estético, por encima de Pacheco y otros artistas. Este es, quizá, el ejemplo más claro de nostalgia estética del sevillano, ya que su cultura visual no puede ser mera casualidad. Con esta obra sobre los ermitaños, se convertirá, a su vez en referente o solución formal para Francisco Collantes (Madrid, c.1599 - c.1656), al realizar su San Onofre (Museo Nacional del Prado, c.1645), procedente de la colección real y que muestra dos leones excavando en la entrada de la cueva, y también un cuervo panadero. En la historia del arte se busca, con frecuencia, la máxima erudición historiográfica y, con ello, se pretende equiparar el estado de conocimiento actual al de los artistas de épocas pasadas, sofisticando, en ocasiones, los encargos y la realización material de los mismos. Ocurre en demasía, además, con los grandes maestros como Velázquez, cuya obra está sujeta a múltiples e interesantes interpretaciones. Pero es necesario, siquiera puntualmente, señalar aquellas circunstancias derivadas del medio artístico y que delimitan con mayor exactitud la conformación de la personalidad de los artistas, frecuentemente tan básicas como la memoria fijada en los estándares asumidos en la juventud.

\section{CONCLUSIONES}

Realizado el análisis de ambas pinturas y establecidas las conexiones entre ellas podría sugerirse una intencionalidad concreta al encargo realizado por el conde-duque de Olivares para Velázquez con ocasión de decorar la ermita del Buen Retiro de la que hubo de ocuparse. Para descubrirla es necesario preguntarse, una vez más, por el destinatario de la pintura y qué se pretendía con ella. Si se encuentra una respuesta probable a esos interrogantes podría ratificarse que la elección temática y formal de Velázquez habría sido perfectamente deliberada y madurada, hasta el punto de comprender que la pintura de los ermitaños no es solo un cuadro, sino algo mucho más importante.

Con asiduidad la historiografía ha renombrado al palacio del Buen Retiro "el Escorial del siglo XVII". En esa nomenclatura se destaca, sobre todo, el continente

22 Morales, 1999, p. 14, cree que "La historiografía artística sobre Velázquez ha tratado solo marginalmente de las huellas flamencas en la pintura velazqueña, mientras ha destacado siempre la repercusión de la pintura italiana en su formación definitiva y en la transformación de su arte". 
que posibilita un centro de poder político y un emblema en el que se materializa una particular forma de entender el imperio español y su monarquía. Sin embargo, una fuente más contemporánea a su construcción y desarrollo destacaba especialmente su papel de retiro espiritual y centro de profesión religiosa. Me refiero a Calderón de la Barca, quien en su auto sacramental El nuevo palacio del Retiro, escrito para el Corpus de 1634 -mismo año en que se cree sería realizada la pintura de los ermitaños de Velázquez-, mostraba el nuevo palacio como símbolo del reino de los cielos (Brown y Elliot, 1981-2003, p. 105). En cualquier caso, "no era infrecuente en la corte española una mezcla, a veces sorprendente, de lo sagrado y lo profano" (Brown y Elliot, 19812003, p. 105). A ello corresponde saber que los reyes visitaban el recinto con ocasión de las celebraciones litúrgicas anuales, sobre todo en tiempos de Cuaresma y Semana Santa, ya que el principal objetivo que se tuvo a la hora de construirlo fue el de servir de reclusión espiritual de los monarcas, que debían desunir, siquiera esporádicamente, sus vidas del peso inherente a su rango (Brown y Elliot, 1981-2003, p. 227) ${ }^{23}$. Y este privilegio no solo estaba asociado con los monarcas, sino con el propio valido. Habría que recordar que la identificación de Olivares con el Buen Retiro era total, de hecho, "le ofrecía un discreto retiro para sí mismo" (Brown y Elliot, 1981-2003, p. $93)^{24}$, puesto que contaba en el complejo con algunos apartamentos, que no utilizaba tantas veces como hacía uso de la ermita de San Juan, destinada a la residencia del alcaide del palacio real. En esos lugares, meditaba durante la Cuaresma o volvía sobre sus libros buscando solución a los problemas de gestión o consuelo intelectual, casi a diario. De manera muy adecuada, el Buen Retiro le ofrecía un ineludible alivio para las obligaciones de su cargo, ya que se trataba de una monarquía en la que el factor religioso tenía un papel fundamental, no solo desde el punto de vista teórico o de las creencias, sino también en la dimensión práctica, pues se recurría a la contemplación meditativa como medio para alcanzar la virtud del buen gobierno.

Habría sido muy interesante conocer el ulterior desarrollo del Buen Retiro, pero la caída de Olivares tras los graves sucesos ocurridos en la crisis de 1640, secó rápidamente el transcurso de la actividad en el palacio y provocó una rápida decadencia que no acabaría de solventarse nunca. En cualquier caso, los testimonios apuntan a que Olivares tenía interesantes planes para llevar a cabo, entre los que concierne a nuestros efectos, el proyecto de establecer una orden de caballeros mixta (seglar y religiosa), cuyo centro neurálgico, un convento, tendría que encontrarse en el Retiro, para cuya sede quizá se utilizara una de las ermitas de los santos anacoretas ${ }^{25}$. Con este dato, cabe preguntarse si Felipe IV iba a ser el gran maestre - ¿quién si no?-, de esta orden con el conde-duque como su gran canciller ${ }^{26}$. Es muy probable que Olivares lo

23 Los reyes pasaban en el Retiro unos cuarenta días al año, cfr. Rodríguez, 2009-2010, p. 142.

24 Rodríguez, 2009-2010, p. 140, considera a Olivares una suerte de ermitaño-cortesano.

25 Brown y Elliot, 1981-2003, p. 228, creen que podría ser equivalente a la del Espíritu Santo fundada en 1578 por Enrique III de Francia.

26 Podría haber seguido, quizá, el mismo organigrama de la Real y Militar Orden de San Hermenegildo. Vid. Sánchez, 2018, pp. 64-67. 
hubiera conseguido, ya que, hasta el estallido de esa fatídica crisis política, “iqué dócil discípulo del Conde Duque había resultado ser el rey!” (Brown y Elliot, 1981-2003, p. 43). Por todo lo anterior, sería legítimo preguntarse si para ese anhelado centro de culto no habría sido elegida la ermita de San Pablo, ya que contaba, sin duda, con la pintura de mayor calidad de todas las que se hicieron para adorno del conjunto, y, quizá, la más adecuada por temática. A esta premisa ayuda pensar en el aprecio que el rey profesaba por la pintura de Velázquez y que, seguramente, se acercara con frecuencia hasta allí para deleitarse con la bella representación del encuentro de los dos ermitaños. Si esto fuera cierto podría pensarse que el valido hubiera ideado algo idóneo y lleno de significancia para ese caso, y que se descubriera así, como auténtico, autor ideológico del lienzo ${ }^{27}$.

Quizá el conde-duque, en el desarrollo de su amplio programa iconográfico palaciego, eligiera para esta ermita -construida seguramente para albergar las pretensiones anteriormente señaladas-, un tema como este, que reunía a dos santos en una prueba serena de sacrificio, entrega y fidelidad cristiana. Un asunto que conocería Olivares desde sus años en Sevilla, gracias a Pedro de Campaña, y que sería recuperado aquí para la corte. Exhortado por su protector, Velázquez ofreció la respuesta más pertinente y oportuna a la situación planteada, convencido seguramente de que la pintura sevillana del manierismo -a la que pertenecía Campaña-, era la que mejor respondía a la necesidad de ejecutar un cuadro que no era un simple tema de devoción, sino que debía ser fuente de reflexión erudita y meditación contemplativa. Tras las formas sencillas, claras y directas que se encierran en el cuadro -que participan, al fin y al cabo, del propio entorno físico al que pertenece la ermita-, se encierra un potente contenido que contribuye a recuperar los espacios dedicados al eremitismo en la España de la Edad Moderna con intención de alcanzar un ideal de vida católica, del que participaba, de manera inequívoca, tanto su majestad como su valido. Ellos tomaban, a su vez, los ejemplos respectivos, de los primeros ermitaños -San Pablo y San Antonio Abad, representantes máximos del monacato primitivo-, para actualizarlos en el Buen Retiro, cuyos jardines habían trocado los de tipo manierista -jalonados de monumentos o elementos curiosos como grutas o cascadas-, en uno de tipo cristiano donde los gobernantes pueden serlo llevando una vida contemplativa. Es la idea del príncipe hispano, católico y austero que recurre al desierto como medio de purificación y alcance de la virtud para conseguir el buen gobierno, buscando el ejemplo en la intervención de la Divina Providencia, propiciada por el alejamiento voluntario del "Siglo" donde habita el hombre y su perdición. Ese sería el motivo para el protagonismo del paisaje dentro del cuadro: el hecho de que el asunto de la pintura figuraría en medio de un bosque o parque, dejando de manifiesto así la intención de

27 El grupo de sevillanos -formado por Francisco de Rioja, Francisco de Calatayud, Juan de Jáuregui, Juan de Fonseca y Figueroa y Diego Velázquez-, era muy fuerte en Madrid con Olivares. No cambiaron la arquitectura de la corte, sino algo más sutil: "la tradición de generoso mecenazgo de las letras y las artes características de Sevilla, la espléndida capital del mundo atlántico, que supo después explotarla para magnificar la majestad del rey". Cfr. Brown y Elliot, 1981-2003, p. 45. 
Velázquez de no separar al rey, paseante y penitente, de la contemplación de la naturaleza al entrar en la ermita para rezar y ver el cuadro al suponer un bosque dentro del bosque ${ }^{28}$. Por ello, mientras que en el cuadro de Campaña se daba más protagonismo a las figuras, en el de Velázquez se refuerzan los elementos circunstanciales, formando un revestimiento más expresivo y significante. En cuanto a esto último, la reunión -después de muchos años de búsqueda, como cuentan las fuentes-, de San Pablo y San Antonio aglutina una serie de valores morales -quizá un programa doctrinal cortesano-, no escogidos al azar, sino seleccionados por su función sostenedora para la monarquía hispánica de Felipe IV y Olivares: sucesión de la corona, alimento provisto desde lo alto, intervención providencial y, en última instancia, un ejemplo y camino de conducta.

En cuanto a Velázquez y su obra magistral, solo restaría decir que, con este encargo -uno de los pocos de tipo religioso que acometió durante su periodo en la corte-, se ilustra uno de los más acerados aciertos de la cultura visual como elemento fundamental y básico en la formación del genio creador de un artista. Algo que no solo contribuye a conformar un repertorio de referencias compositivas, sino que manifiesta en la elección de unas formas y otras la voluntad de afiliarse a determinadas maneras de entender y hacer la pintura, heredadas, en su caso, por su maestro Pacheco, que le enseñó a emular a Campaña como una forma válida de pintar. Esto no le quita ningún mérito al sevillano, ni por haber recibido el tema y la referencia de Olivares, ni por haber actualizado el mensaje de Campaña, ya que nada es absolutamente nuevo cuando hay creación, puesto que, en el Barroco, los condicionantes son muy importantes para cumplir esas necesidades. En cualquier caso, con esta pintura Velázquez le otorga un nuevo status a Campaña, uno que aún no tenía en Sevilla ni en los territorios flamencos, y lo hizo en el centro mismo del poder, de la cultura y de la religión en España: el Palacio del Buen Retiro, un complicado puzle, cuyo estudio aun sigue ofreciendo interesantes nociones a las que, consideraciones como estas, pueden contribuir a terminar de conformar la idea de la monarquía hispánica en ese ámbito.

\section{BIBLIOGRAFÍA}

Angulo Î́niguez, Diego (1947-1999). Velázquez. Cómo compuso sus principales cuadros y otros escritos sobre el pintor. Madrid: Laboratorio de Arte, Universidad de Sevilla, $2^{\text {a }}$ edición: Madrid, Istmo.

28 Otras destacadas pinturas de paisajes se dispusieron en el palacio. Me refiero a las de Claudio de Lorena, Nicolás Poussin, Gaspar Dughet, Jean Lemaire, Herman van Swanevelt, Jan Both, Martínez del Mazo, Agüero y Collantes, llamadas, con frecuencia, los cuadros de staffage. El gusto francés del siglo XVII convirtió el paisaje en un elemento protagonista donde se insertaban las historias de manera circunstancial. En ellos los personajes pierden presencia en el paisaje, ya que este actúa a veces como anestésico ante la contemplación de la historia que se relata, como si se tratara de una celosía que permite observar aquello que se selecciona. Cfr. Rodríguez, 2009-2010, p. 141. Ni que decir tiene que, en su actual contexto museográfico se pierde todo su sentido original. 
Angulo Îniguez, Diego (1951). Pedro de Campaña. Madrid: Laboratorio de Arte, Universidad de Sevilla.

Baceiredo Rodríguez, María Isabel y López Madroñero, Mauricio J. (1997): "Restauración de la Tabla de San Antonio Abad y San Pablo Ermitaño de Pedro de Campaña", Cuadernos de restauración, $\mathrm{n}^{\circ}$ 0, pp. 21-29.

Brown, Jonathan (1986). Velázquez. Pintor y cortesano. Madrid: Alianza Forma.

Brown, Jonathan y Elliot, J.H. (1981-2003). Un palacio para el rey. El Buen Retiro y la corte de Felipe IV. Madrid: Revista de Occidente, $2^{\text {a }}$ edición revisada y ampliada: Madrid: Taurus.

Campo Francés, Ángel del (1983). "La hipótesis conquense de los ermitaños de Velázquez", Archivo español de arte, n² 224, pp. 387-397.

Ceán Bermúdez, Juan Agustín (1800). Diccionario histórico de los más ilustres profesores de las Bellas Artes en España. Madrid: Real Academia de Bellas Artes de San Fernando.

Gállego, Julián (1990). “47. San Antonio Abad y San Pablo, primer ermitaño” en Domínguez Ortiz, Antonio, Pérez Sánchez, Alfonso E. y Gállego, Julián (dirs.): Velázquez. Cat. exp. Madrid, Museo Nacional del Prado, p. 284.

Harris, Enriqueta (2006). Estudios completos sobre Velázquez. Madrid: Centro de Estudios Europa Hispánica.

J.M.S. y L.M.R (1999). Cat. no 4, "San Pablo Ermitaño y San Antonio", en Morales, Alfredo J. (dir.): Velázquez y Sevilla. Cat. exp., Sevilla, Centro Andaluz de Arte Contemporáneo, vol. 2, Catálogo, pp. 22 y 23.

Lleó Cañal, Vicente (1999). "El Velázquez sevillano" en En torno a Velázquez. Sevilla: Real Maestranza de Caballería de Sevilla, pp. 73-91.

Maravall, José Antonio (1960-1999). Velázquez y el espíritu de la modernidad. Madrid: Guadarrama, 2a edición: Madrid, Ministerio de Educación y Cultura.

Marías, Fernando (2019). "Dando de comer a Cristo y bendiciendo la mesa: entre Francisco Pacheco y el joven Diego Velázquez”, Laboratorio de arte, nº 31, pp. 265-284.

Morales Martínez, Alfredo J. (1999): "Flandes e Italia en la pintura sevillana de Velázquez" en En torno a Velázquez. Sevilla: Real Maestranza de Caballería de Sevilla, pp. 13-29.

Pacheco, Francisco (1599-1985). Libro de descripción de verdaderos retratos de ilustres y memorables varones. Sevilla, edición e introducción de Pedro M. Piñero Ramírez y Rogelio Reyes Cano. Diputación de Sevilla.

Pereda, Felipe (2017). Crimen e ilusión. El arte de la verdad en el Siglo de Oro. Madrid: Marcial Pons.

Ponz, Antonio (1792). Viage de España, en que se da noticia de las cosas más apreciables, $y$ dignas de saberse, que hay en ella. Madrid: Joaquín Ibarra, Viuda de Ibarra, Hijas y Compañía, $2^{\text {a }}$ impresión. 
Rodríguez G. de Ceballos, Alfonso (2009-2010). "Velázquez y las ermitas del Buen Retiro: entre el eremitismo religioso y el refinamiento cortesano", Atrio, no 15-16, pp. $135-148$.

Sánchez de Toca Alameda, Melchor (2018). "Una reflexión sobre la Real y Militar Orden de San Hermenegildo", Ejército de tierra español, no 928, pp. 64-67.

Serrera, Juan Miguel (1999). "Velázquez y la pintura sevillana de su tiempo" en Morales, Alfredo J. (dir.): Velázquez y Sevilla. Cat. exp., Sevilla, Centro Andaluz de Arte Contemporáneo, Estudios, pp. 50-59.

Valdivieso, Enrique (2008). Pedro de Campaña. Sevilla: Fundación Sevillana Endesa.

Velázquez in Seville (1996) en Davies, D. Harris, E. y Clarke, M.(dirs.), cat.exp. Edimburgo, National Gallery of Scotland.

Vilar, Pierre (1963). Historia de España. París: Librairie Espagnole.

Vorágine, Santiago de la (2008). La leyenda dorada. Madrid: Alianza. 
